\title{
A Study of Emotional Intelligence, Experienced Bullying and Psychological Well-Being among Secondary School Students from Boarding Schools
}

\author{
Neha Kulkarni ${ }^{*}$, Dr Sairaj Patki ${ }^{2}$
}

\section{ABSTRACT}

The research was conducted to study the differences between male and female Secondary school students on the aspects of emotional intelligence, psychological Well-being and experienced bullying from boarding schools. The sample was collected from two boarding schools. The sample size was 84 , with 47 male students and 37 female students .The students selected had studied in the particular school for a minimum period of three years. The tools selected for data collection were Emotional Intelligence Test by Ekta Sharma, Psychological well-being index by Harold Dupuy and Multidimensional peer victimization scale by Stephen Joseph. The scores for central tendency were obtained by calculating mean, SD, skewness and kurtosis. The scores were not normally distributed. No significant gender differences were observed. Emotional intelligence was found to be positively correlated with psychological well-being and Experienced Bullying was found to be negatively correlated with well-being.

Keywords: Emotional Intelligence, Psychological well-being, Experienced Bullying, Boarding School.

Emotional Intelligence - EQ - is a relatively recent behavioural model, rising to prominence with Daniel Goleman's 1995 Book called 'Emotional Intelligence'. It is the ability to perceive emotion, integrate emotion to facilitate thought, understand emotions and to regulate emotions to promote personal growth. During the 1970s and 80s by the work and writings of psychologists Howard Gardner (Harvard), Peter Salovey (Yale) and John 'Jack' Mayer (New Hampshire).Emotional Intelligence is increasingly relevant to organizational development and developing people, because the EQ principles provide a new way to understand and assess people's behaviours, management styles, attitudes, interpersonal skills, and potential. Emotional Intelligence is an important consideration in human resources planning, job profiling, recruitment interviewing and

\footnotetext{
${ }^{1}$ Research Scholar, Modern College, Department of Psychology, Pune, India

${ }^{2}$ Assistant Professor, Symbiosis College, Department of Psychology, Pune, India

*Responding Author

(C) 2016, N Kulkarni, S Patki; licensee IJIP. This is an Open Access Research distributed under the terms of the Creative Commons Attribution License (http://creativecommons.org/licenses/by/2.0), which permits unrestricted use, distribution, and reproduction in any Medium, provided the original work is properly cited.
} 


\section{A Study of Emotional Intelligence, Experienced Bullying and Psychological Well-Being among Secondary School Students from Boarding Schools}

selection, management development, customer relations and customer service, and more. Emotional Intelligence links strongly with concepts of love and spirituality: bringing compassion and humanity to work, and also to 'Multiple Intelligence' theory which illustrates and measures the range of capabilities people possess, and the fact that everybody has a value. The EQ concept argues that IQ, or conventional intelligence, is too narrow; that there are wider areas of Emotional Intelligence that dictate and enable how successful we are. Success requires more than IQ (Intelligence Quotient), which has tended to be the traditional measure of intelligence, ignoring essential behavioural and character elements. We've all met people who are academically brilliant and yet are socially and inter-personally inept. And we know that despite possessing a high IQ rating, success does not automatically follow. The following steps describe the five components of Emotional Intelligence as developed by Daniel Goleman.

\section{The Five Components of Emotional Intelligence}

1. Self-awareness is the ability to recognize and understand Personal moods and emotions and drives and their effects on others. Hallmarks of self-awareness include self-confidence, realistic self-assessment, and a self-deprecating sense of humour. Self-awareness depends on one's ability to monitor one's own emotional state and the correct identification of one's own emotions. Selfawareness is necessary for realistic self-assessment. The presence of realistic self-assessment is a sufficient to conclude that there is self-awareness.

2. Self-regulation is the ability to control or redirect disruptive impulses and moods, and the propensity to suspend judgement and to think before acting. Hallmarks include trustworthiness and integrity; comfort with ambiguity; and openness to change.

3. Internal motivation is the passion to work for internal reasons that go beyond money and status which give are external rewards, - such as an inner vision of what is important in life, a joy in doing something, curiosity in learning, a flow that comes with being immersed in an activity. A propensity to pursue goals with energy and persistence. Hallmarks include a strong drive to achieve, optimism even in the face of failure, and organizational commitment

4. Empathy is the ability to understand the emotional makeup of other people. A skill in treating people according to their emotional reactions. Hallmarks include expertise in building and

retaining talent, cross-cultural sensitivity, and service to clients and customers. In an educational context, empathy is often thought to include, or lead to, sympathy, which implies concern, or care or a wish to soften negative emotions or experiences in others.

5. Social skills. Proficiency in managing relationships and building networks, and an ability to find common ground and build rapport. Hallmarks of social skills include effectiveness in leading change, persuasiveness, and expertise building and leading teams.

\section{Psychological well-being}

Psychological well-being refers to how people evaluate their lives. According to Diener (1997), these evaluations may be in the form of cognitions or in the form of affect. The cognitive part is 


\section{A Study of Emotional Intelligence, Experienced Bullying and Psychological Well-Being among Secondary School Students from Boarding Schools}

an information based appraisal of one's life that is when a person gives conscious evaluative judgments about one's satisfaction with life as a whole. The affective part is a hedonic evaluation guided by emotions and feelings such as frequency with which people experience pleasant/unpleasant moods in reaction to their lives. The assumption behind this is that most people evaluate their life as either good or bad, so they are normally able to offer judgments. Further, people invariably experience moods and emotions, which have a positive effect or a negative effect. Thus, people have a level of subjective well-being even if they do not often consciously think about it, and the psychological system offers virtually a constant evaluation of what is happening to the person. Following are the components of well-being.

1. Self-acceptance

2. Personal growth

3. Purpose in life

4. Environmental mastery

5. Autonomy

6. Positive relations with others

\section{Experienced Bullying}

Bullying is a form of aggressive behaviour in which someone intentionally and repeatedly causes another person injury or discomfort. Bullying can take the form of physical contact, words or more subtle actions. The bullied individual typically has trouble defending him or herself and does nothing to "cause" the bullying. Following are the types of bullying that are often reported to occur:

1. Physical Bullying: Includes physical aggression in the form of causing physical injury or hurt in order to exercise intimidation.

2. Verbal Bullying: Includes calling names or using foul language to demean them.

3. Social Manipulation: In this type of bullying, the aggressor seeks to manipulate social situations for the victim by spreading untrue rum ours, refusing to speak to them or by trying to get them into trouble on purpose.

4. Property attacks: This type of bullying occurs primarily in boarding schools. The aggressor might steal, damage some object of the victim.

\section{Boarding School}

A boarding school is a school where some or all pupils study and live during the school year with their fellow students and possibly teachers or administrators. The word 'boarding' is used in the sense of "bed and board," i.e., lodging and meals. Some boarding schools also have day students who attend the institution by day and return off-campus to their families in the evenings. Many independent (private) schools in the Commonwealth of Nations are boarding schools. Boarding school pupils (a.k.a. "boarders") normally return home during the school holidays and, often, weekends, but in some cultures may spend the majority of their childhood and adolescent life away from their families. In the United States, boarding schools comprise various grades, most commonly grades seven or nine through grade twelve - the high school years. Specialized 


\section{A Study of Emotional Intelligence, Experienced Bullying and Psychological Well-Being among Secondary School Students from Boarding Schools}

military schools also feature military education and training. Some American boarding schools offer a post-graduate year of study in order to help students prepare for college entrance, most commonly to assimilate foreign students to American culture and academics before college.

\section{History of Boarding School}

The practice of sending children to other families or to schools so that they could learn together is of very long standing, recorded in classical literature and in UK records going back over a thousand years. In Europe, a practice developed by early mediaeval times of sending boys to be taught by literate clergymen, either in monasteries or as pages in great households. The school often considered the world's oldest boarding school, The King's School, Canterbury, counts the development of the monastery school in around $597 \mathrm{AD}$ to be the date of the school's founding. The author of the Croyl and Chronicle recalls being tested on his grammar by Edward the Confessor's Queen Editha in the abbey Cloisters as a Westminster schoolboy, in around the 1050s. Monastic schools as such were generally dissolved with the monasteries themselves under Henry VIII, although for example Westminster School was specifically preserved by the King's letters patent and it seems likely that most schools were immediately replaced. Winchester College founded by Bishop William of Wykeham in 1382 and Oswestry School founded by David Holbache in 1407 are the oldest boarding schools in continual operation.

\section{Statement of the Problem}

"To study emotional intelligence, experienced bullying and psychological well-being Among Secondary school students from boarding schools”

\section{About The Present Study}

The present study aims to study the emotional intelligence, experienced bullying and Psychological well-being of students from boarding school. Peer victimization and bullying have been problems that have produced generations of victims. Often, the bullying experience stays with many victims, influencing their various decisions in life. Children, at times, do not inform adults or caretakers that they are being bullied. This study could help in identifying the nature and the extent of experienced bullying. It will also help in identifying the vulnerable students who are afraid to speak up. Bullying is not unheard of in Indian schools, however, there are no stringent laws against it.

\section{Overview}

Some people have no choice but to send their children to boarding or residential schools because of occupational or lifestyle reasons. It is a big change for the child as they are no longer in the protective arms of their parents. The positive effects of studying in a boarding school include discipline, as boarding school imbibes a sense of discipline in Children, and good habits such as waking up early and exercise are developed automatically. The children learn to be more 


\section{A Study of Emotional Intelligence, Experienced Bullying and Psychological Well-Being among Secondary School Students from Boarding Schools}

responsible and become independent. However, the negative effects include bullying which could largely affect the well-being of an individual. The psychological impact of these experiences is immense. It leaves them unprepared for relationships in adult life It has been reported that emotionally intelligent children experience a broad range of emotions which they use for information and to maintain healthy relationships. Those who lack emotional intelligence are prone to poorer mental health, higher propensity to use illegal substances and increased aggressive behaviour.

\section{REVIEW OF LITERATURE}

1. Rigby, Ken (2000) Effects of peer victimization in schools and perceived social support on adolescent well-being. Is mental health of schoolchildren undermined by repeated bullying at school and further exacerbated by having inadequate social support? Hypothesis was investigated by administering the General Health Questionnaire (GHQ) to 845 adolescent school children attending coeducational secondary schools in South Australia, together with measures of the extent to which each reported being bullied at school and the social support available to them. Multiple regression analyses indicated that for both the sexes frequent per victimization and low social support contributed significantly and independently to relatively poor mental health.

2. Sharp, Sonia (1995) examined the effects of bullying on adolescents and the coping strategies adolescents employed when confronted by bullies. Hypothesis was investigated by administering questionnaire concerning self-esteem, sociability, bullying experiences and their response to it, and coping strategies to 703 secondary school students (aged 13-16). It was reported that bullying was stressful, particularly indirect verbal bullying.44\% of school students merely felt irritated because of bullying, whereas approximately one-third of school students continued to feel panicky and nervous in school, experienced recurring memories of the incident, and reported impaired concentration in school. Coping strategies varied widely and included passive (i.e., walking away) and aggressive (fighting) and assertive (standing up for themselves without any aggression) behaviours

3, Beran, Tanya N. \& Tutty, Leslie.(2002): The purpose of this research was to determine the frequency of bullying in elementary school children and to examine gender and age differences. Self-report data of bullying was administered on a total of 472 students in grades 1-6 in Calgary, Alberta completed. The frequency of bullying was somewhat higher than previously reported by others. In grades 4 to 6, 27\% experienced both physical and verbal bullying, 21\% experienced verbal bullying, and 5\% reported physical bullying. Reports of bullying experienced by students in grades 1 to 3 were similar. A stepwise regression analysis indicated that higher perceived school safety and more teacher support were associated with less verbal bullying 4. Sharp, Sonia., Thompson., Arora, Tiny (2000)Long-term bullying is an area which has not been specifically investigated. Yet, its consequences and susceptibility to change may be very different from short-term bullying episodes. This article sets out to look at some of the issues

(C) The International Journal of Indian Psychology, ISSN 2348-5396 (e)| ISSN: 2349-3429 (p) | 16 


\section{A Study of Emotional Intelligence, Experienced Bullying and Psychological Well-Being among Secondary School Students from Boarding Schools}

involved and draws on the findings of two studies, both of which have relevance to the phenomenon of long-term bullying. The first findings are those of a follow-up study which looked at the progress of anti-bullying policies in secondary schools. The second findings are from a pilot study which investigated students' feelings about long-term bullying. The outcomes of these studies suggest that a small percentage of students may be bullied for a long period of time and that this more persistent bullying may need focused, long-term solutions to resolve it. 5. Greeff, Paul (2004). The Nature and prevalence of Bullying. This study was conducted to acquire descriptive information regarding the nature and prevalence of school bullying in the intermediate school phase. To achieve this, the Revised Olweus Bully/Victim Questionnaire (ROBVQ) was used as a self-report measure to investigate bullying across five different dimensions: exposure to various forms of bullying/harassment; forms of bullying behaviour; where bullying occurs; characteristics of the bullies and whether the social environment had been informed about the bullying. The total sample comprised 360 grade four to six learners from English-medium, single-sex schools in Bloemfontein. To ensure a more homogeneous sample the grade (grades four to six) and race (black and white) of the participants were controlled. All statistical analyses were done by means of frequencies and cross-tabulations using the chi-square statistical test with grade, gender and ethnicity as independent variables. The results were generally similar to those reported by most international studies of school bullying, namely: that self-reported bullying decreases with advancement in grades; that the most prevalent form of bullying is verbal bullying; that boys reported experiencing direct physical bullying more than girls did and that the most likely location for bullying to occur is the playground. Furthermore, boys generally reported being made fun of and teased in a hurtful way, as well as being kicked, hit and pushed more frequently than girls. It was also found that black learners reported experiencing racial bullying significantly more than white learners. Black boys reported experiencing racist bullying more than black girls did. Both girls and boys indicated being bullied most by learners in their own class, with boys also being bullied by learners from higher grades. White learners indicated being bullied most by learners in the same class, whereas black learners reported being bullied equally by learners from the same class and learners from a higher grade. The study also yielded a much higher rate of bullying $(56,4 \%)$ than those cited in previous South African as well as international research. The high rate of bullying revealed in the study makes it necessary to conduct future research into bullying, as ways need to be found to lessen the deleterious effects of bullying on learners' school careers, both of the bullies and their victims.

6. N. Carlisle, E. Refes (2007) Pilot Study of adult males who were bullied at schools in United States, Australia, United Kingdom. 6 out of the 15 participants were bullied at boarding school. Study is qualitative, with quantitative evaluation of survey data. Participants attribute significant and lasting effects to their school bullying, notably in high levels of shames and relational difficulties. 


\section{A Study of Emotional Intelligence, Experienced Bullying and Psychological Well-Being among Secondary School Students from Boarding Schools}

7. Gabriel, O. Kehnide (2013) to investigate the psychological effects of bullying on victims or bullying acts using self report methods. Negative Act Scale and Symptom Distress Checklist were used to manifestations of emotional distress among respondents. The sample includes both boarders and non-boarders aged between 12 and 19. It showed higher incidences of bullying among boys than girls. It showed significant correlations with bullying and ten symptoms of distress were investigated.

8. Neupane, Dasrath (2014) Gender role in school bullying. The general aim of this research was to analyse the relationship between bullying and victimization with response to gender. Pen and paper self-report survey was administered to nepali adolescents in Kathmandu. It measured criterion variables bullying and victimization. Participants were drawn from three private schools in Kathmandu. The number of students participated were 104. Study investigated prevalence of bullying in school with reference to gender. The results from the survey indicate that the boys are more bullies than girls. Boys have reported higher mean scores of physical, verbal bullying. On the other hand, girls have reported higher mean scores of indirect bullying and victimization. Gender differences in bullying and victimization were as expected.

\section{Objectives}

1. To study the levels of emotional intelligence experienced bullying, and psychological wellbeing among secondary-school students from boarding schools

2. To study the relationship between emotional intelligence and psychological well-being while controlling for experienced bullying.

3. To study gender differences in emotional intelligence experienced bullying, and General psychological well-being among secondary school students studying in boarding schools.

\section{Hypotheses}

1. There is no difference between male and female students on Emotional Intelligence.

2. There is no difference between male and female students on Experienced Bullying.

3. There is no difference between male and female students on Psychological well-being.

4. Emotional Intelligence is positively correlated with Psychological Well-being.

5. Experienced bullying is negatively correlated with Psychological well-being.

\section{Significance}

This study will be beneficial to the victims of bullying. It will aid the institutions in devising the intervention techniques needed to help the student. It will also help to identify students who are more vulnerable and prone to bullying and are afraid to seek help.

\section{Rationale}

A meta-analysis study shows that 'bully victims' are at a greater risk for psychosomatic problems than non-bullied age mates. Given that school bullying is a widespread phenomenon it should be considered a significant international public health problem. (Gini\& Pozzoli, 2013) Studied have also shown that peer victimisation is significantly associated with suicidal ideation 


\section{A Study of Emotional Intelligence, Experienced Bullying and Psychological Well-Being among Secondary School Students from Boarding Schools}

(Rigby, 2003). Emotional Intelligence education is considered to be an effective way to deal with bullying. Emotional intelligence is the ability to recognize, understand, label, express, and regulate emotions, one's own emotions and those of others. It means effective strategies for managing feelings, expressing even negative emotions in appropriate ways, and behaving compassionately. These skills can be taught, just like mathematics or reading. EI seems to play an important role in both bullying behaviour and victimization. EI education could greatly improve bullying prevention and intervention initiatives, as it teaches empathy and compassion. (Mckenna, J. \& Webb, J , 2013) Teachers can learn how to impart these crucial skills to students through school-wide approaches that simultaneously create supportive and caring climates for learning and focus on emotional skill development. Emotional intelligence training is appropriate for all ages, from pre-scholars to high scholars. In schools that teach emotional intelligence, the results speak for themselves. These schools tend to report an increase in academic success, better teacher-student relationships, and a decrease in problem behaviour, including bullying. In classrooms that use the emotional intelligence approach, students become more likely to show empathy to others, to choose kind actions instead of cruel ones, and to acknowledge their emotions. These students also ask teachers for help when emotions are overwhelming. In short, students with emotional intelligence training learn to navigate their complex social and emotional worlds with insight, empathy, and kindness. (Rivers, 2014)Research has shown that individuals, who have been persistently subjected to abusive behaviour are at the risk of stress related illnesses which can lead to suicide, anxiety, and self-esteem. It is, therefore, important to study the effects of bullying and ways to avoid it. Bullying is also detrimental to student's wellbeing and development. Bullying has long been a part of the boarding school ethos, particularly in boys institutions. As a result many children are suffering in secret physical and psychological intimidation. Thus, it is important to identify such victims of bullying and victimization.

\section{METHODOLOGY}

This chapter describes the research methodology used in this study. It covers the hypotheses formulated on the basis of available literature, operational definitions of the variables, the sample and sampling technique, the data collection method followed, tools used for data collection and the statistical analyses performed.

\section{Sample}

A total of 130 questionnaires were administered in both the schools out of which only 84 could be retained owing to the inclusion criteria of including only those students who had completed 3 or more years in that particular boarding school. Some questionnaires were filled incompletely and hence could not be taken into consideration. The sample contained grades 7th, 8th, 9th, 10th, students of English medium co-ed boarding schools. 


\section{A Study of Emotional Intelligence, Experienced Bullying and Psychological Well-Being among Secondary School Students from Boarding Schools}

\section{Variables}

\section{VARIABLES FOR COMPARATIVE ANALYSIS}

\section{I.V: Gender}

D.Vs: Emotional Intelligence, Experienced Bullying, Psychological Well-being

\section{VARIABLES FOR CORRELATIONAL ANALYSIS}

Predictor variables: Emotional Intelligence, Experienced Bullying

Criterion variable: Psychological well-being

\section{Operational Definitions}

1. Emotional Intelligence in this study is comprised of five domains, 'self-awareness', 'managing Emotions', 'motivating oneself', 'handling relationships' and 'empathy'. The emotional intelligence is then hypothesized as being positively correlated with psychological well-being. The emotional Intelligence is regarded as the ability to monitor oneself and one's emotions. In the study, having a Good measure of emotional intelligence is crucial as it could help prevent bullying behaviour.

2. Psychological well-being refers to how people evaluate their lives. In this study, the aspect of Well-being is studied with respect to emotional intelligence and bullying in boarding school Secondary students.

3. Experienced Bullying; Bullying is a form of aggressive behaviour in which someone intentionally and repeatedly causes another person injury or discomfort. Bullying can take the form of physical contact, words or more subtle actions. The bullied individual typically has trouble defending him or herself. In this study, the aspect of bullying is studied in boarding school students and correlated with aspects of emotional intelligence and well-being.

\section{Tools}

1. The Personal Data Sheet for this study was included in the questionnaire to obtain relevant demographic details about the participants. It included details of Class, division, gender, and the variables; duration of time in school in years, happiness in school and academic achievement.

2. The Emotional Intelligence Test was used to assess the emotional intelligence of secondary school students. The test was devised in 2011 by author Ekta Sharma. It has 60 items with five domains, 'Self Awareness, Managing Emotions, Motivating Oneself, Empathy, and Handling Relationships. It contains five options: Always, Most Often, Occasionally, Rarely, Never. It has test-retest reliability, Criterion-related validity, and content validity, construct validity between 0.362 to 0.837 . Age norms include 10-17 age categories.

3. Psychological General Well-being Index, The test contains 22 items with six options. Some items are negatively marked. The author of the test is Harold Dupuy. It measures six dimensions: Anxiety, Depressed Mood, Positive Well-being, Self-control, General Health, and Vitality. 4. Multidimensional Peer-Victimization Scale, It contains 16 items. The author of the test is 


\section{A Study of Emotional Intelligence, Experienced Bullying and Psychological Well-Being among Secondary School Students from Boarding Schools}

Stephen Joseph. It measures four dimensions: Verbal, Physical, Social Manipulation and Attack on property.

\section{Procedure}

- The research was conducted to study emotional intelligence, experienced Bullying, and psychological well-being among secondary school students from boarding Schools.

- The data collection was obtained in the months of July and September with the prior Permissions of the principals of the two institutions.

- A sample of 84 was selected for the same, with 47 males and 37 females’ students studying in Boarding school.

- The questionnaires was administered in the classrooms

- The rapport was established, the subjects were given EIT, then PGWBI and then Multidimensional Peer-Victimization scales in English.

- The scoring was done as per the manuals.

- After the scoring, the analysis was done with the help of SPSS 22

\section{Statistical Analysis}

The scores for central tendency were obtained by calculating mean, SD, skewness and kurtosis. It was found that scores were not distributed normally. Therefore, Mann-Whitney U was used to compare male and female students on emotional intelligence Experienced bullying and psychological wellbeing and Spearman correlation was done with the help of SPSS 22.

\section{ANALYSIS AND DISCUSSION}

\section{Table showing mean, median, SD, Skewness and kurtosis of Male and Female students:}

\begin{tabular}{|l|l|l|l|l|l|l|}
\hline & \multirow{2}{*}{\begin{tabular}{l} 
Mean \\
\cline { 5 - 7 }
\end{tabular}} & Deviation & \multicolumn{2}{l|}{ Skewness } & \multicolumn{3}{l|}{ Kurtosis } \\
\cline { 5 - 7 } & Statistic & Std. Error Statistic & Std. Error \\
\hline Happiness about School & 1.61 & .560 & -1.069 & .263 & .175 & .520 \\
\hline Academic Performance & 1.60 & .623 & -1.289 & .263 & .590 & .520 \\
\hline Duration in School & 4.25 & 1.559 & 1.525 & .263 & 2.094 & .520 \\
\hline Self-Awareness & 32.57 & 7.442 & -.139 & .263 & -.373 & .520 \\
\hline Managing Emotions & 24.24 & 6.849 & .767 & .263 & .197 & .520 \\
\hline Motivating Oneself & 43.92 & 10.875 & -.588 & .263 & -.358 & .520 \\
\hline Empathy & 34.64 & 6.572 & .110 & .263 & -.408 & .520 \\
\hline Handling Relationships & 65.00 & 11.193 & -.625 & .263 & -.337 & .520 \\
\hline Total-EI Score & 200.37 & 18.722 & .326 & .263 & .330 & .520 \\
\hline Physical Victimization & 2.11 & 2.313 & .926 & .263 & -.079 & .520 \\
\hline Verbal Victimization & 3.02 & 2.260 & .675 & .263 & -.418 & .520 \\
\hline Social Manipulation & 2.56 & 2.130 & .697 & .263 & -.176 & .520 \\
\hline
\end{tabular}


A Study of Emotional Intelligence, Experienced Bullying and Psychological Well-Being among Secondary School Students from Boarding Schools

\begin{tabular}{|l|l|l|l|l|l|l|}
\hline & & \multirow{2}{*}{$\begin{array}{l}\text { Std. } \\
\text { Mean }\end{array}$} & \multicolumn{3}{|l|}{ Skewness } & \multicolumn{3}{l|}{ Kurtosis } \\
\cline { 5 - 8 } & Deviation & Statistic & Std. Error Statistic & Std. Error \\
\hline Attack on Property & 2.82 & 2.309 & .482 & .263 & -.739 & .520 \\
\hline Total-Bullying Score & 10.48 & 7.225 & .944 & .263 & .632 & .520 \\
\hline Psychological Wellbeing & 66.73 & 15.185 & .004 & .263 & .602 & .520 \\
\hline
\end{tabular}

The table above includes the descriptive statistics of the study. The variables; Happiness about School, Academic Achievement, Duration of school were Included in the Personal Data Sheet, to collect the demographic details of the Participants. The means of the variables are 1.611 .604 .25 respectively. The emotional Intelligence mean score is 200.37 for both the gender which falls in the category of 'average' which implies that the participants of both the genders have an average range of emotional Intelligence. The mean of the bullying score is 10.48 which implies that students have experienced a significant form of bullying .The general well-being of the students is 66.73. It implies an above average score. The maximum score attained is 110, which represents the best achievable 'well-being'.

\section{Inferential Statistics}

The non-parametric tests of Mann-Whitney $U$ were used for comparative gender studies and Spearman's rho correlation was used for correlational analysis. The non-parametric tests were used as scores were not normally distributed.

\section{DISCUSSION}

\section{Comparison of Emotional Intelligence between male and female students}

\begin{tabular}{|l|l|l|l|l|}
\hline Variables & Gender & Mean Rank & $\begin{array}{l}\text { Mann- } \\
\text { Whitney } \\
\text { U }\end{array}$ & Significance \\
\hline 1. Self-awareness & Girls & 43.31 & 839.500 & .787 \\
\cline { 2 - 4 } & Boys & 41.86 & & \\
\hline \multirow{2}{*}{ 2.Managing emotions } & Girls & 42.72 & 861.500 & .942 \\
\cline { 2 - 3 } & Boys & 42.33 & & \\
\hline \multirow{2}{*}{ 3.Motivating Oneself } & Girls & 44.12 & 809.500 & .588 \\
\cline { 2 - 3 } & Boys & 41.22 & & \\
\hline 4.Empathy & Girls & 41.68 & 839.500 & .783 \\
\cline { 2 - 3 } & Boys & 43.15 & & \\
\hline \multirow{2}{*}{ 5. Handling Relationships } & Girls & 41.53 & 833.500 & .745 \\
\cline { 2 - 3 } & Boys & 43.27 & & \\
\hline \multirow{2}{*}{ Total EI score } & Girls & 41.80 & 843.50 & .815 \\
\cline { 2 - 3 } & Boys & 43.05 & & \\
\hline
\end{tabular}




\section{A Study of Emotional Intelligence, Experienced Bullying and Psychological Well-Being among Secondary School Students from Boarding Schools}

The first hypothesis of the research states that there is no significant difference between male and female students on Emotional Intelligence. The mean rank of the male students was found to be 43.05 and of female students, it was found to be 41.08. The $U$ score is 843.500 and the significance is .815 at 0.05 level. So, statistically no differences were observed between male and female students. No significant differences were found on the domains of Self Awareness, Managing Emotions, Motivating Self, Empathy and Handling Relationships. Hence, the null hypothesis was retained. Emotional Intelligence (EI) is the ability to manage and monitor emotions of others and your own. These findings are in contrast with most of the existing literature in the world, it should however be noted that the research was conducted on adolescents and a growing body of research states that emotional intelligence develops with age and that older people are slightly more likely to be higher on emotional intelligence. (Fariselli, Ghini \& Freedman, 2006)

\section{Comparison of Experienced Bullying among male and female students}

\begin{tabular}{|l|l|l|l|l|}
\hline Variables & Gender & Mean Rank & $\begin{array}{l}\text { Mann-Whitney } \\
\text { U }\end{array}$ & Significance \\
\hline $\begin{array}{l}\text { 1.Physical } \\
\text { victimization }\end{array}$ & Girls & 40.64 & 800.500 & .520 \\
\cline { 2 - 3 } $\begin{array}{l}\text { 2. Verbal } \\
\text { Victimization }\end{array}$ & Goys & 43.97 & & \\
\cline { 2 - 3 } $\begin{array}{l}\text { 3.Social } \\
\text { Manipulation }\end{array}$ & Boys & 46.51 & 721.000 & .176 \\
\hline \multirow{2}{*}{$\begin{array}{l}\text { 4.Attackon } \\
\text { property }\end{array}$} & Girls & 49.34 & 862.000 & .945 \\
\cline { 2 - 3 } 5.Total Bullying & Girls & 42.66 & & \\
\cline { 2 - 3 } & Boys & 43.16 & 845.000 & .823 \\
\cline { 2 - 3 } & Girls & 41.98 & & .867 \\
\hline
\end{tabular}

According to the second hypothesis of the research, there is no significant differences on male and female students on experienced bullying. The mean rank of the male students was found to be 42.11 and that of female students was found to be 43.00 . The $U$ score was 861.000 and the significance is .867 at 0.05 level. Thus, the null hypothesis was retained as no significant differences were reported even on the domains of verbal, physical, social and property attacks. Bullying is a form of aggressive behaviour in which someone intentionally and repeatedly causes another person injury or discomfort. Although no significant differences are seen, it is seen that girls score slightly higher than boys on verbal victimization, as female students have scored a mean rank of 46.51 and male students have scored a mean rank of 39.34 with a U score of 721.000 and significance is .176 at 0.05 level. One of the reasons why boys might found to be high on bullying in the existing literature could be that the definitions of bullying often involve physical and social aggression but do not include other types of bullying as the methods of bullying could be entirely different. It is often reported that bullying done by girls is done in a 


\section{A Study of Emotional Intelligence, Experienced Bullying and Psychological Well-Being among Secondary School Students from Boarding Schools}

more discreet manner Such as verbal assaults by the usage of verbal attacks (name-calling, gossip, insults, etc.) to target their victims. Another method is exclusion. Girls often form groups of similar social status and shun other girls who try to join. Scare tactics and cyber bullying is also not often included in the definition of bullying. ( Zundel Irene, 2000) Also, due to the possibility of fear of future attacks, the male students might have hesitated to give honest responses.

4 Comparison of Psychological well-being between male and female students

\begin{tabular}{|l|l|l|l|l|}
\hline Variables & Gender & Mean Rank & Mann-Whitney U & Significance \\
\hline Psychological well-being & Girls & 44.34 & 801.500 & .504 \\
\hline & Boys & 41.05 & & \\
\hline
\end{tabular}

According to the third hypothesis of the research, there is no significant difference between male and female students on psychological well-being. The mean rank of the male students is 41.05 and for the female students it is 44.35 with a $\mathrm{U}$ score of 801.500 and the significance is.504 at 0.05 level. Thus, no significant differences are observed and the hypothesis is supported. The popular view is that there are gender differences in this domain. However, in some researches, the gender similarities hypothesis, which holds that males and females are similar on most, but not all, psychological variables. Gender differences can substantially vary in magnitude and depend upon the context in which the measurement occurs. (Hyde, J.S, 2005)

\section{Table showing correlations}

\begin{tabular}{|l|l|}
\hline & Psychological Wellbeing \\
\hline Total-EI Score & $.348^{* *}$ \\
\hline Total-Bullying Victimization Score & $-.364^{* *}$ \\
\hline
\end{tabular}

$* *=\mathrm{p}<.01$

The fourth hypothesis states that emotional intelligence is positively correlated with Psychological Well-being. As seen in the above table, spearman's rho correlation was found significant at $.348^{* *}$ at 0.01 level. Thus, the hypothesis was supported. Satisfaction and psychological well-being can be characterized as good mental health functioning (Argyle,1987) Emotionally intelligent children experience a broad range of emotions and they use this information to maintain healthy relationships. They experience greater well-being and fewer instances of depression, anxiety and aggression. (Brackett \& Rivers, 2014) The fifth hypothesis states that experienced bullying is negatively correlated with psychological well-being. As seen in the above table, spearman's rho correlation was found significant at $-364^{* *}$ at 0.01 level. Thus, the hypothesis was supported. It has been well known that bullying at a young age presents a problem for children, parents and teachers alike. However, bully victims are perhaps the most 


\section{A Study of Emotional Intelligence, Experienced Bullying and Psychological Well-Being among Secondary School Students from Boarding Schools}

vulnerable group of all. They are at a great risk for health problems in adulthood, over six times more likely to be diagnosed with serious illness, smoke regularly, or develop a psychiatric disorder compared to those not involved in bullying. (Mikulak, 2013)

\section{Summary}

Results of the present study indicate no significant differences between male and female students on the aspects of emotional intelligence, psychological well-being and experienced bullying. However, emotional intelligence is found to be positively correlated with psychological wellbeing and psychological wellbeing is observed to be negatively correlated with experienced bullying.

\section{CONCLUSIONS}

The first hypothesis of the research states that there is no significant difference between male and female students on Emotional Intelligence. The Mean rank of the male students was found to be 43.05 and of female students, it was found to be 41.08 . The U score is 843.500 and the significance is. 815 at 0.05 level. So, statistically no differences were observed between male and female students. The second hypothesis of the research states that there is no significant differences on male and female students on experienced bullying. The mean rank of the male students was found to be 42.11 and that of female students was found to be 43.00 . The U score was 861.000 and the significance is .867 at 0.05 level. Thus, the null hypothesis was retained as no significant differences were observed.

According to the third hypothesis of the research, there is No significant difference between male and female students on psychological well being. The mean rank of the male students is 41.05 and for the female students it is 44.35 with a $\mathrm{U}$ score of 801.500 and the significance is .504 at 0.05 level. Thus, no significant differences are observed and the null hypothesis is retained. The fourth hypothesis states that emotional intelligence is positively correlated with Psychological Well-being. As seen in the above table, spearman's rho correlation was found significant at $.348^{* *}$ at 0.01 level.

Thus, the hypothesis was supported. Satisfaction and psychological well-being can be characterized as good mental health functioning. The fifth hypothesis states that experienced bullying is negatively correlated with psychological well-being. As seen in the above table, spearman's rho correlation was found significant at $-364^{* *}$ at 0.01 level.

Thus, the hypothesis was supported.

\section{Limitations}

1. The principle limitation of the research was that it was conducted on an unequal proportion of male and female students with 47 male students and 37 female students. 


\section{A Study of Emotional Intelligence, Experienced Bullying and Psychological Well-Being among Secondary School Students from Boarding Schools}

2. The Possibility if sibling(s) studying in the same school was not considered.

3. The Attachment levels with parents was not considered

4. The Availability of social support was not considered

5. Few schools were covered in data collection

6. Perceived school environment/ interaction with teachers was not considered

7. The School-board was not controlled

\section{Implications}

The research was conducted to study gender differences among secondary boarding school students on the aspects of Emotional Intelligence, Psychological wellbeing, Experienced bullying.

- No significant differences were observed between male and female students on emotional intelligence, psychological wellbeing and experienced bullying.

- Results also prove that emotional intelligence is positively correlated with psychological wellbeing.

- Results prove that psychological wellbeing is negatively correlated with experienced bullying.

- Emotional Intelligence skills training can be imparted in curriculum in all schools as it is known to be an effective technique to combat bullying behaviour as it can help the bully victims to stand up for themselves and it can teach the bullies to be more empathetic and to direct their aggression in a better way.

- Emotional Intelligence skills training can also help the children to be more positive and happy which could enhance their outlook and can help them to fight their adolescent issues which could lead to better academic achievement

- Stringent measures need to be taken against bullying in school as the bullying behaviour could continue in colleges in the form of ragging.

\section{Further Directions}

- The present research was conducted in two schools. It can be extended to few more schools.

- The sample taken was of unequal gender groups. The research can be extended by adding more female group samples.

- The research can be made more accurate by controlling variables such as family background and the academic achievement of the sample selected.

\section{Summary}

Results of the present study indicate that bullying in schools can be reduced by giving emotional intelligence education for better mental health and positivity. The results also have their set of limitations which can be improved with further directions. 


\section{A Study of Emotional Intelligence, Experienced Bullying and Psychological Well-Being among Secondary School Students from Boarding Schools}

\section{Acknowledgments}

The author appreciates all those who participated in the study and helped to facilitate the research process.

\section{Conflict of Interests}

The author declared no conflict of interests.

\section{REFERENCES}

Argyle, M.(1987). The psychology of happiness. London: Methuen.

Brackett, M \& Rivers, S (2014) Preventing Bullying with Emotional Intelligence. Education Week.

Gabriel, O. Kehnide (2013) To investigate the psychological effects of bullying on victims or bullying acts using self report methods

Ghini, Fariselli, Freedman (2006) Age and Emotional Intelligence

Gini \& Pozolli (2013) Bullied Children and psychosomatic problem; A Meta analysis

Greeff, Paul (2004). The Nature and prevalence of Bullying

Hyde, J.S.(2005) ; The Gender Hypothesis Similarities

Ken, Rigby (2000); Effects of peer victimization and perceived social support

Mckenna, J. \& Webb, J. (2013) Emotional intelligence. British Journal of Occupational Therapy, 76(12), 560

Mikulak, A.(2013) ; Far from being harmless, the effects of bullying last well into adulthood

Neupane, Dasrath (2014) Gender role in school bullying ,Beran, Tanya N.\&Tutty, Leslie.(2002): the frequency of bullying in elementary school children and to examine gender and age differences.

How to cite this article: N Kulkarni, S Patki (2016), A Study of Emotional Intelligence, Experienced Bullying and Psychological Well-Being among Secondary School Students from Boarding Schools International Journal of Indian Psychology, Volume 3, Issue 4, No. 68, ISSN:2348-5396 (e), ISSN:23493429 (p), DIP:18.01.193/20160304, ISBN:978-1-365-39398-3 